\title{
Solid-State Kicker Pulser for DARHT-2
}

E. G. Cook, B. S. Lee, S. A. Hawkins, F. V. Allen, B. C. Hickman, J. S. Sullivan, C. A. Brooksby

This article was submitted to 2001 IEEE International Pulsed Power Plasma Science Conference, Las Vegas, NV, June 17-22, 2001

\section{June 7, 2001}

U.S. Department of Energy

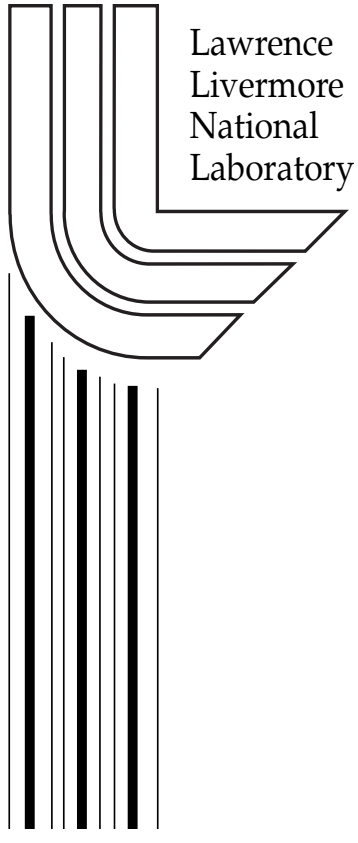




\section{DISCLAIMER}

This document was prepared as an account of work sponsored by an agency of the United States Government. Neither the United States Government nor the University of California nor any of their employees, makes any warranty, express or implied, or assumes any legal liability or responsibility for the accuracy, completeness, or usefulness of any information, apparatus, product, or process disclosed, or represents that its use would not infringe privately owned rights. Reference herein to any specific commercial product, process, or service by trade name, trademark, manufacturer, or otherwise, does not necessarily constitute or imply its endorsement, recommendation, or favoring by the United States Government or the University of California. The views and opinions of authors expressed herein do not necessarily state or reflect those of the United States Government or the University of California, and shall not be used for advertising or product endorsement purposes.

This is a preprint of a paper intended for publication in a journal or proceedings. Since changes may be made before publication, this preprint is made available with the understanding that it will not be cited or reproduced without the permission of the author.

This work was performed under the auspices of the United States Department of Energy by the University of California, Lawrence Livermore National Laboratory under contract No. W-7405-Eng-48.

This report has been reproduced directly from the best available copy.

Available electronically at http://www.doc.gov/bridge

Available for a processing fee to U.S. Department of Energy

And its contractors in paper from

U.S. Department of Energy

Office of Scientific and Technical Information

P.O. Box 62

Oak Ridge, TN 37831-0062

Telephone: (865) 576-8401

Facsimile: (865) 576-5728

E-mail: reports@adonis.osti.gov

Available for the sale to the public from

U.S. Department of Commerce

National Technical Information Service

5285 Port Royal Road

Springfield, VA 22161

Telephone: (800) 553-6847

Facsimile: (703) 605-6900

E-mail: orders@ntis.fedworld.gov

Online ordering: http://www.ntis.gov/ordering.htm

OR

Lawrence Livermore National Laboratory

Technical Information Department's Digital Library

http://www.llnl.gov/tid/Library.html 


\title{
Solid-State Kicker Pulser for DARHT-2*
}

\author{
E. G. Cook, B. S. Lee, S. A. Hawkins, E. M. Anaya, F. V. Allen, B. C. Hickman, J. S. Sullivan \\ Lawrence Livermore National Laboratory-7000 East Ave., Livermore, CA 94550 \\ C. A. Brooksby \\ Bechtel Nevada - P.O.Box 2710, Livermore, CA 94550-9230
}

\begin{abstract}
To replace a hard tube design, a solid-state kicker pulser for the Dual-Axis Radiographic Hydrodynamic Test facility (DARHT-2) has been designed and tested. This kicker modulator uses multiple solid-state modules stacked in an inductive-adder configuration where the energy is switched into each section of the adder by a parallel array of MOSFETs. The modulator features very fast rise and fall times, pulse width agility and a high pulse-repetition rate in burst mode. The modulator can drive a $50 \Omega$ load with voltages up to $20 \mathrm{kV}$ and can be easily configured for either positive or negative polarity. The presentation will include test and operational data.
\end{abstract}

\section{BACKGROUND}

The DARHT-2 accelerator facility is designed to generate $1 \mathrm{kA}$ electron beam pulses of $2 \mu \mathrm{s}$ duration. The LLNL designed fast kicker, based on cylindrical electromagnetic stripline structures, chops four short pulses out of this long pulse. The fast kicker requires both positive and negative polarity pulses. The requirements for the pulser that drives this kicker are listed in Table 1.

Table 1. Pulser Performance Requirements

\begin{tabular}{|l|l|}
\hline \multicolumn{1}{|c|}{ Parameter } & \multicolumn{1}{c|}{ Requirement } \\
\hline Output Voltage & 20kV into 50 $\Omega$ \\
\hline Voltage Rise/Fall-time & $\leq 10 \mathrm{~ns}(10-90 \%)$ \\
\hline Flattop Pulse-width & $\begin{array}{l}16 \mathrm{~ns}-200 \mathrm{~ns} \mathrm{(continuously} \\
\text { adjustable) }\end{array}$ \\
\hline Burst Rate & $\begin{array}{l}\text { 4 pulses @ 1.6MHz( 600ns } \\
\text { between leading edges) }\end{array}$ \\
\hline
\end{tabular}

A $10 \mathrm{kV}$ modulator design based on planar triodes was originally used for this application [1]. While the hardtube performance was very good, concerns regarding future availability and reliability of these devices led to consideration of a solid-state replacement. Personnel within the Beam Research Program at LLNL had developed considerable expertise with parallel and series arrays of power MOSFETs during the successful design and testing of the Advanced Radiograph Machine (ARM) modulator, a high power pulser developed to show feasibility of solid-state modulators for driving induction accelerators [2]. While ARM was designed for higher voltages and currents than required by the kicker, its requirements for rise and fall times were also significantly slower. After consideration of various circuit topologies and types of solid-state devices, a variation of the adder configuration used by ARM was selected as the baseline for the kicker modulator; MOSFETs were selected as the solid-state switching device.

The key parameter in the performance requirement is the minimum pulsewidth of 16ns. As a class of devices, $1 \mathrm{kV}$ rated MOSFETs have demonstrated the required rise and falltime; however, the critical information needed was a determination of whether MOSFETs are capable of switching significant current while simultaneously achieving the required minimum pulsewidth. Device datasheets do not necessarily provide all the information required to make a definitive decision: testing is essential.

\section{DEVICE EVALUATION AND SELECTION}

In order to keep the total number of devices required to a reasonable value, it is important to minimize the number of series elements. Therefore only MOSFETs capable of operation at voltages of $\geq 700$ volts were considered for testing. The MOSFET evaluation circuit was a series circuit consisting of a low inductance DC capacitor bank, a resistive load, and the MOSFET. Devices were evaluated on the basis of switching speed (turn-on and turn-off) at various peak currents, waveshapes, minimum output pulsewidth, and ease of triggering. Extensive testing of many devices from several vendors produced several that were acceptable and led to the selection of the APT1001RBVR. During testing, this device exhibited the cleanest rise and fall waveshapes and met the pulsewidth, risetime, and falltime requirements. We were also able to measure a peak current of $\sim 35$ amperes before seeing an unacceptable drain-source voltage drop (we arbitrarily chose a voltage drop of $<20$ volts during conduction of the current pulse as our acceptance criteria). The APT1001RBVR has a $1000 \mathrm{~V}$ maximum drain to source rating, an average current rating of $10 \mathrm{~A}$, and a pulsed current rating of 40A. This device is available in a standard TO-247 package.

During the early testing of MOSFETs, it became apparent that the MOSFET gate drive circuit was also an essential element in achieving the best performance from the individual devices. The coupling between the drive circuit and the MOSFET had to have very low loop inductance, as the peak drive current required to achieve fast switching performance was on the order of tens of amperes. Even the devices within the gate drive circuit had to be very fast and have short turn-on and turn-off delay times. An early decision was that each MOSFET

*This work performed under the auspices of the U.S. Department of Energy by University of California Lawrence Livermore National Laboratory under contract No. W-7405-Eng-48. 
would require its own dedicated gate drive. A simplified schematic of the drive circuit is shown in Fig. 1. The input device of the gate drive has a level-shifting TTL input circuit internally coupled to a MOSFET totem pole output. This circuit drives a fast, high current MOSFET (peak current \pm 20 amperes) totem pole device which drives the gate of the power MOSFET (capacitive load) to turn it on and sinks current from the MOSFET to turn it off. The gate drive circuit components require a dc voltage of $\sim 15$ volts.

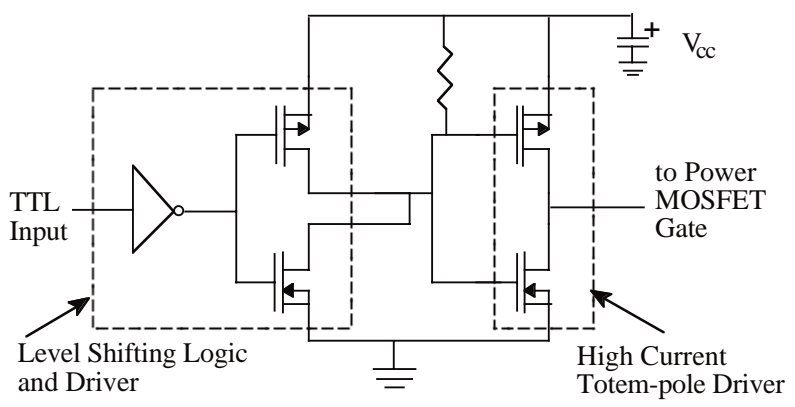

Figure 1. Simplified Schematic of MOSFET Drive Circuit

\section{CIRCUIT TOPOLOGY}

In the adder configuration shown in Fig. 2, the secondary windings of a number of $1: 1$ pulse transformers are connected in series. Typically, for fast pulse applications, both the primary and secondary winding consists of a single turn to minimize the leakage inductance. In this configuration, the output voltage on the secondary winding is the sum of all the voltages appearing on the primary windings.

In the primary-side circuit, the source impedance of the MOSFET array and the DC capacitor bank must be very low $(<<1 \Omega)$ to be able to provide the total secondary current, any additional current loads in the primary circuit, plus the magnetization current for the transformer core. The layout for this circuit is important as it is necessary to minimize total loop inductance - it doesn't take much inductance to affect performance when the switched di/dt is on the order of $40 \mathrm{kA} / \mu \mathrm{s}$. The loop inductance is controlled by mounting the high-power components on printed circuit boards and using wide conductor traces with supply and return current paths on opposite sides of the board.

The MOSFETs shown in Fig. 2 have their source lead connected to ground. This is chosen so that all the gate drive circuits are also ground referenced, thereby eliminating the need for floating and isolated power supplies. The pulse power ground and the drive circuit ground have a common point at the MOSFET source connection but otherwise do not share common current paths; thereby reducing switching transients being coupled into the low-level gate drive circuits.

Excessive voltage transients can be generated by energy stored in the stray loop inductance, energy stored in the transformer primary, and/or voltage coupled into the primary circuit from the secondary (usually due to trigger timing differences in stages of the adder). Transient protection for the MOSFETs is provided by the series combination of snubber capacitor and diode tightly coupled to the MOSFET. The capacitor is initially charged to the same voltage as the DC capacitor bank. When the MOSFET is turning on, the diode prevents the snubber capacitor from discharging through the MOSFET. As the MOSFET turns off, transient voltages that may exceed the voltage on the snubber capacitor turn the diode on so that the capacitor can absorb the energy. The parallel resistor allows the excess capacitor voltage to discharge into the DC capacitor between bursts. Good performance of the over-voltage circuit requires a low inductance capacitor and a diode with a low forward recovery voltage.

Not shown in the simplified circuit layout is the reset circuit for the magnetic cores. The cores require reset so that they do not saturate during a voltage pulse. As this circuit operates in a well defined pulse format, it is not necessary to actively reset the core between pulses. Consequently, a DC reset circuit is used and is implemented by connecting a DC power supply through a large isolation inductor to the ungrounded end of the secondary winding of the adder stack. In the interval between bursts, the reset current will reset and bias the magnetic cores. This approach is simple to incorporate and requires few additional components but has the disadvantage of requiring the transformer to have sufficient magnetic core material to sustain the entire burst stream.

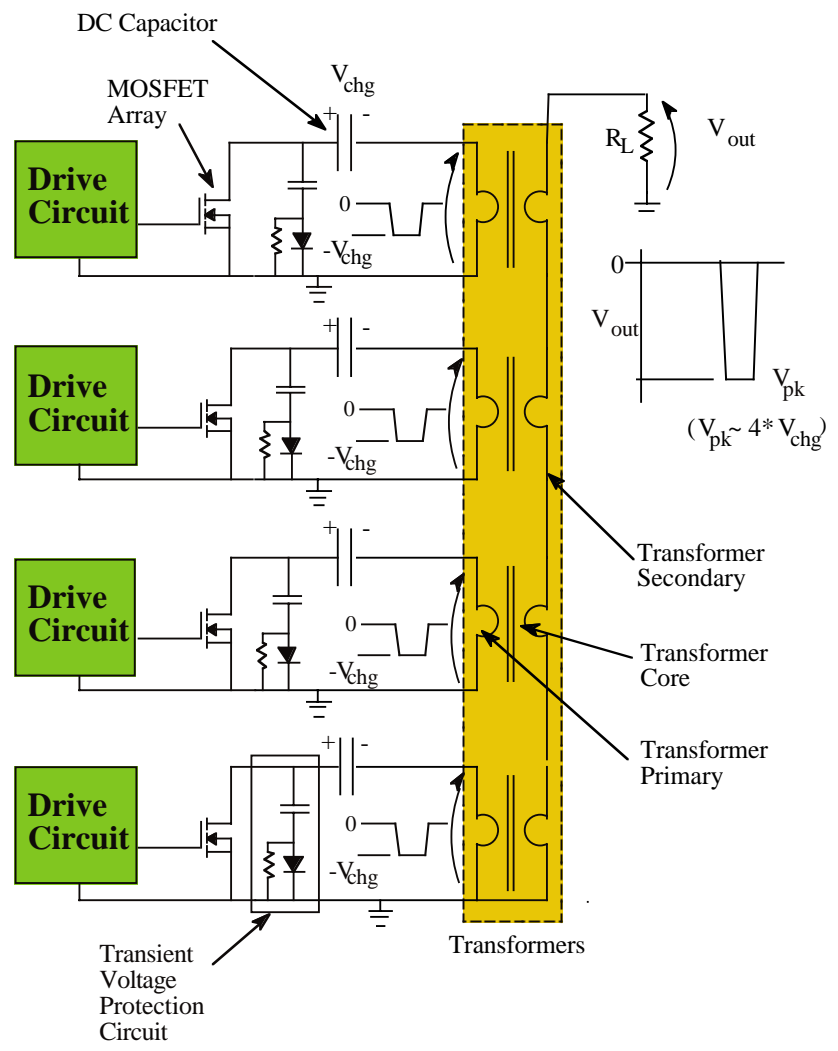

Figure 2. Simplified Schematic of Adder Circuit - Four Adder Cells Shown 


\section{TRANSFORMER DESIGN AND COMPONENT LAYOUT}

The adder transformer is designed to look very much like an accelerator cell of a linear induction accelerator with the primary winding totally enclosing the magnetic core (an annealed and Namlite insulated Metlgas ${ }^{\circledR} 2605$ S1A tapewound toroid purchased from National/Arnold). As shown in Fig. 3, the input drive connection between the transformer primary and ground has sliding contacts that make electrical connections to a printed circuit board (pcb) when the pcb is inserted between the contacts. Two boards (designated MOSFET carrier boards) are inserted into the transformer from opposite sides. Modules of this configuration are stacked (toroid center axis vertical) to form the adder with the number of modules determining the final output voltage.

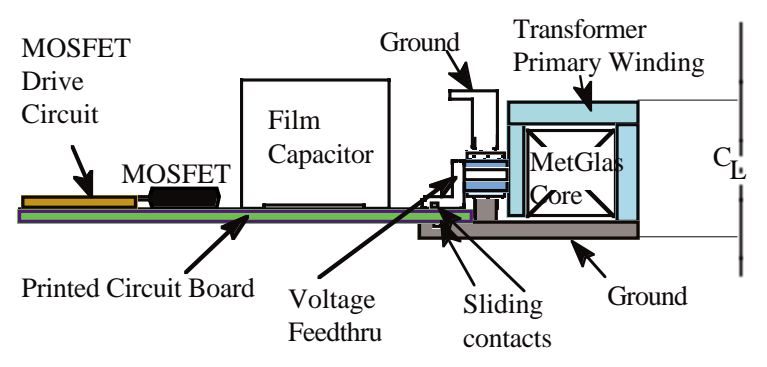

Figure 3. Simplified Cross-Section of the Pulse Transformer with PCB Inserted

Each MOSFET carrier board is laid out to have six pairs of MOSFETs symmetrically arranged in a circular pattern such that identical current paths exist. Controlling total loop inductance for each MOSFET ensures that all devices switch the same peak currents. Also mounted on the pcb are the MOSFET gate drive circuits, the DC storage capacitors and the snubber circuits. Each module has a total of 24 MOSFETS which gives a comfortable margin in peak current capability that allows for extra loading in the primary circuit, a reasonable magnetization current, and total load current. A photograph of one MOSFET carrier board inserted into a transformer assembly is shown in Fig. 4. The gate drive circuit boards (one dedicated to each MOSFET) receive their trigger pulses from a single trigger circuit (also mounted on the MOSFET carrier board) which is connected to an external pulse generator by coaxial cable.

A complete kicker adder assembly consisting of a stack of transformer assemblies bolted together is shown in Fig. 5. The MOSFET carrier boards are shown inserted into the transformer assemblies. This modular configuration is intended to allow for easy maintenance; in the event of a component failure, the entire board can be replaced in minutes. The secondary winding for the pulser is usually a metal rod that is positioned on the axial centerline of the adder stack. The rod may be grounded at either end of the adder stack to generate an output voltage of either polarity. The $50 \Omega$ high-voltage output cable enters the pulser from the top of the enclosure.

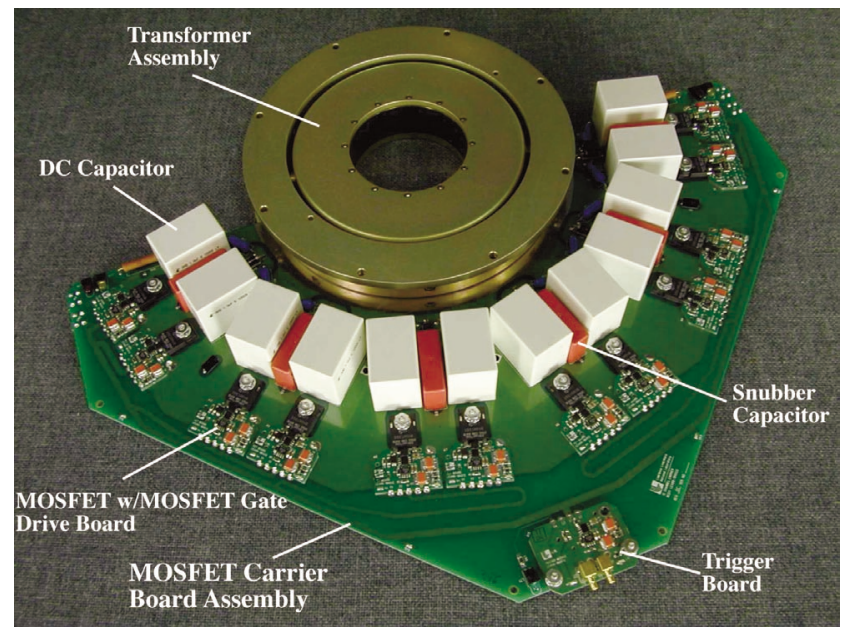

Figure 4. Transformer Assembly. With One MOSFET Carrier Board Inserted

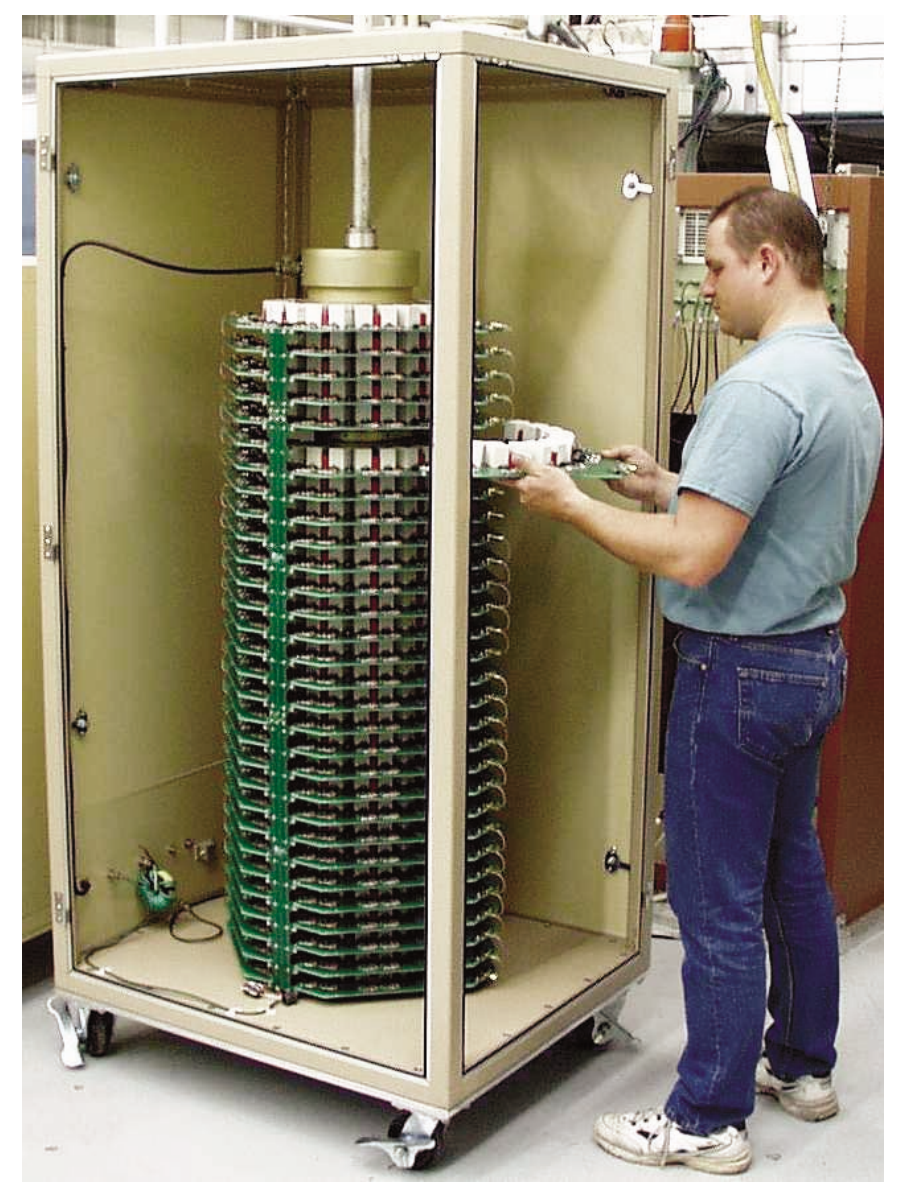

Figure 5. Kicker Pulser Assembly with MOSFET Carrier Boards Installed 


\section{Test Results}

The modulator is undergoing extensive testing into both resistive loads and into the kicker structure used on the ETA II accelerator at LLNL. The modulator has been operated at variable pulse-widths and at burst frequencies exceeding $5 \mathrm{MHz}$. All data are measurements for the pulser while driving a $50 \Omega$ load resistance. Single pulse data at $18 \mathrm{kV}$ and $20 \mathrm{kV}$, as shown in Fig. 6 and Fig. 7, demonstrate the performance with regard to pulse waveshape and rise and fall times. The four-pulse burst in Fig. 8 demonstrates the pulsewidth agility of the modulator at variable burst frequency: the burst format is generated by an arbitrary waveform generator. Fig. 9 is a plot of the output voltage of both the positive and negative polarity pulsers when triggered from the same source.

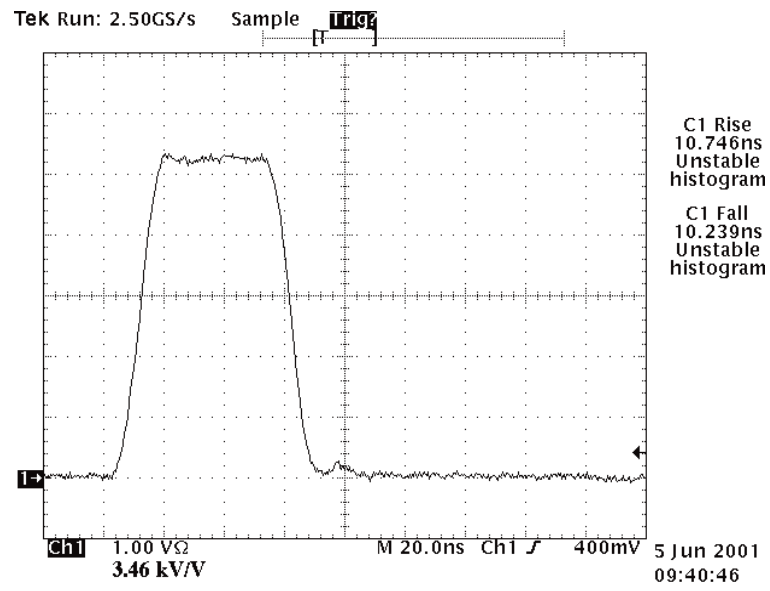

Figure 6. Single Pulse at $\sim 18 \mathrm{kV}, 30 \mathrm{~ns}$ Pulse Width

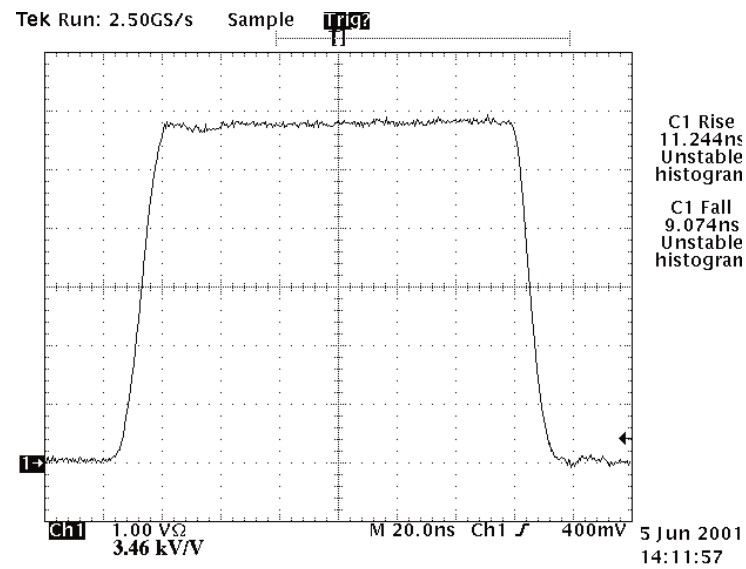

Figure 7. Single Pulse at $\sim 20 \mathrm{kV}, 120$ ns Pulse Width

\section{CONCLUSIONS}

A fast kicker pulser based on MOSFET switched adder technology has been designed and tested. MOSFET arrays in an adder configuration have demonstrated the ability to generate short duration and very fast risetime and falltime high-voltage pulses.

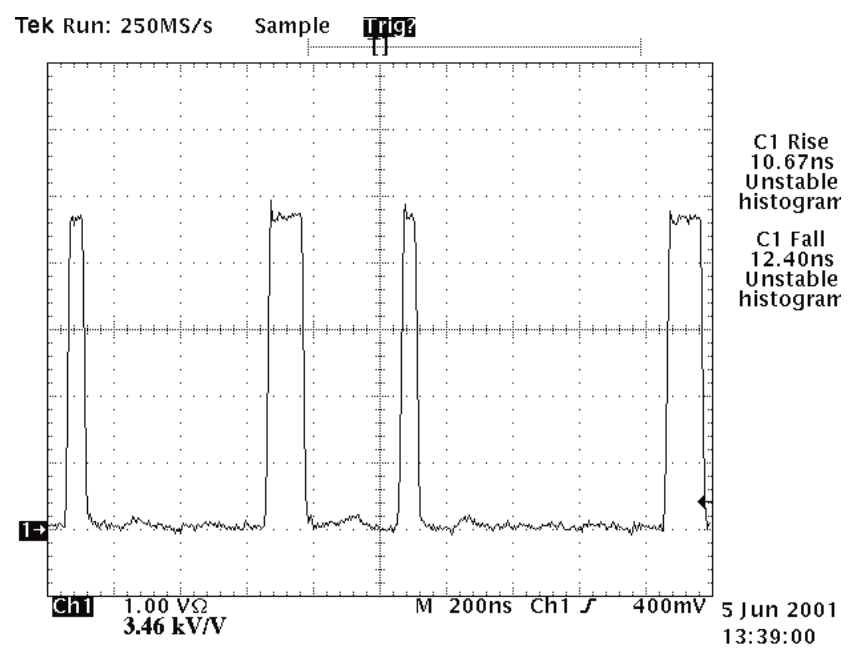

Figure 8. Four Pulse Burst at $\sim 16 \mathrm{kV}-30 \mathrm{~ns}$ and 100ns Pulse Width

Positive and Negative Modulator Triggered Together (50ns Pulse) Vcharge $=620 \mathrm{~V}$

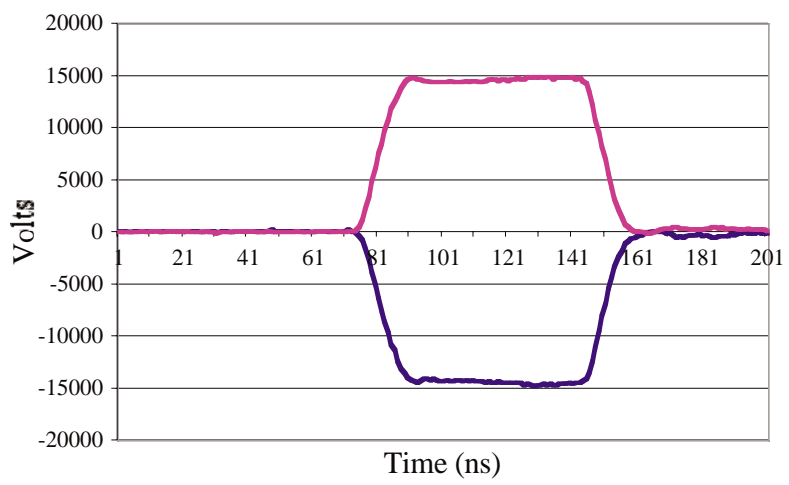

Figure 9. Simultaneous Measurement of Outputs of Positive and Negative Polarity Pulsers

\section{REFERENCES}

[1] W.J. DeHope, et al, "Recent Advances in Kicker Pulser Technology for Linear Induction Accelerators," $12^{\text {th }}$ IEEE Intl. Pulsed Power Conf., Monterey, CA, June 27-30, 1999.

[2] H.C. Kirbie, et al. "Development of Solid-State Induction Modulators for High PRF Accelerators," Lawrence Livermore National Laboratory, Livermore, CA, UCRL-JC-119582, Proceedings of the $10^{\text {th }}$ IEEE Pulsed Power Conference, Albuquerque, NM, July 10-13, 1995.

[3] J.A. Watson, et al, "A Solid-State Modulator for High Speed Kickers," Particle Accelerator Conference 2001, Chicago, IL, June 25-29, 2001. 